\title{
Teoria Final, Unificação e Reducionismo: Opiniões da Comunidade Brasileira de Física
}

Final Theory, Unification and Reductionism: views of the Brazilian community of physics

\author{
Arden Zylbersztajn \\ Departamento de Física - UFSC
}

Recebido em 20 de setembro, 2002. Aceito em 26 de novembro, 2002.

\begin{abstract}
A primeira parte do artigo consta de uma breve discussão centrada nas idéias de Steven Weinberg, um defensor da unificação reducionista, e que acredita que a física de partículas e campos já tenha trilhado boa parte do caminho em direção a uma teoria final, e de Philip Anderson, um crítico de posturas reducionistas, que trouxe para a física a visão emergentista. Na segunda parte são apresentados resultados de uma pesquisa realizada com o propósito de investigar qual a receptividade que idéias como "unificação", "reducionismo" e "teoria final", encontram entre membros da comunidade de físicos no Brasil. Os resultados indicam uma tendência de rejeição à possibilidade de uma teoria final e, em menor grau, ao reducionismo, sendo a idéia de unificação mais aceitável.
\end{abstract}

The first part of the paper introduces a brief discussion centered on the ideas of Steven Weinberg, who defends reductionist unification and believes that the physics of particles and fields had already moved a large part of the way towards a final theory, and of Philip Anderson, a critic of reductionist positions, who brought the emergentist view to physics. In the second part, results of a survey on how ideas such as "unification", "reductionism" and "final theory" are received by members of the Brazilian community of physicist are presented. The results show a tendency of rejection of the possibility of a final theory and, to a lesser degree, of reductionism, the idea of unification being more acceptable.

\section{Introdução}

No final de seu famoso livro de divulgação científica Stephen Hawking, abusando de uma metáfora talvez mais do que seria razoável, afirmou que se uma teoria unificada completa for descoberta:

“...ela deverá, ao longo do tempo, ser compreendida, grosso modo, por todos e não apenas por alguns poucos cientistas. Então devemos todos, filósofos, cientistas, e mesmo leigos, ser capazes de fazer parte das discussões sobre a questão de por que nós e o universo existimos. Se encontrarmos a resposta para isto teremos o triunfo definitivo da razão humana; porque, então, teremos atingido o conhecimento da mente de Deus." (Hawking, 1988, pág. 238)

Jan Hilgevoord, que editou uma série de palestras sobre o tema, considera que a visão de Hawking sobre Deus e suas afirmações relacionando Deus a uma teoria física final não podem ser consideradas representativas da atitude da maioria dos físicos. Ao mesmo tempo, porém, destaca que a crença daquele cientista de que a física possa chegar à elaboração de uma "Teoria de Tudo" definitiva é compartilhada por muitos de seus pares, concluindo que:

"É difícil, então, deixar de pensar nas consequiências que uma teoria como essa teria sobre nossa visão de mundo e nosso papel nele como criaturas que seriam capazes de descobrir esta verdade definitiva sobre o mundo." (Hilgevo- ord, 1994, pág. 2)

A relevância do assunto para o ensino de física foi apontada por Pleitez (2000), ao chamar a atenção para a importância que discussões sobre a procura de leis fundamentais pode ter tanto para estudantes de graduação de pósgraduação, ajudando-os a escolher e a valorizar suas áreas de trabalho, como para a educação do público em geral. Igualmente, se aceitarmos que um dos papeis da educação é o de promover o entendimento da ciência enquanto parte da formação cultural (Zanetic 1989), ganha força o argumento de que tal objetivo ficará incompleto, se não forem consideradas as controvérsias que muitas vezes estão imbricadas com o desenvolvimento das teorias científicas. No entanto, controvérsias importantes nem sempre são devidamente consideradas na formação de futuros licenciados e bacharéis em física, como mostrou Mota (2000) no caso do ensino da mecânica quântica, uma assepsia que em nada contribui para a compreensão mais ampla do empreendimento científico.

Este artigo pretende contribuir no sentido de reforçar a inclusão de uma controvérsia atual, cujos eixos principais foram delineados em Pleitez (2000), no quadro de discussões da área de ensino de física. A primeira parte apresenta a controvérsia, destacando as idéias de Steven Weinberg, um defensor do ideal unificador reducionista, que acredita que a física de partículas e campos já tenha trilhado boa 
parte do caminho em direção a uma teoria final, e de Philip Anderson, um crítico das posturas reducionistas, que trouxe para a física a visão emergentista. $\mathrm{Na}$ segunda parte são apresentados resultados de uma pesquisa realizada com o propósito de investigar qual a receptividade que idéias como "unificação", "reducionismo" e "teoria final" encontram entre membros da comunidade de físicos no Brasil.

\section{A controvérsia: teoria final unifi- cada, reducionismo e emergência}

A idéia de que a física esteja se aproximando da elaboração de uma teoria unificada, capaz de fornecer uma base final para a compreensão dos fenômenos naturais, tem sido objeto de consideração por parte de cientistas de renome. Uma "Teoria de Tudo", como passou a ser denominada a unificação fundamental, é imaginada como sendo subjacente a todos os fenômenos naturais. O mais conhecido, persistente e intelectualmente sofisticado defensor da possibilidade de elaboração de uma teoria deste tipo é Steven Weinberg, que recebeu (juntamente com Abdus Salam e Sheldon Glashow) o Prêmio Nobel de Física em 1979 por seu trabalho na área de partículas elementares, particularmente pelo desenvolvimento da teoria das interações eletrofracas.

Dentre os cientistas que acreditam na possibilidade da Teoria de Tudo, Weinberg se destaca, não apenas pela influência de seu trabalho teórico mas também por sua disposição e habilidade em escrever para o público leigo. Antes ainda de ser agraciado com o Nobel ele publicou, em 1977, "The First Three Minutes", e posteriormente em 1993, "Dreams of a Final Theory", uma defesa eloqüente da busca de uma Teoria de Tudo. Com tais credenciais, não é de estranhar que tenha sido convidado para escrever artigos em edições especiais sobre a ciência no final do milênio e o seu futuro, em revistas destinadas a um público amplo, como Scientific American e Time, e recentemente tenha sido matéria de capa do caderno Mais!, que faz parte da edição dominical da Folha de São Paulo (Weinberg 1999, 2000, 2001). Ao mesmo tempo suas posições são analisadas com destaque em trabalhos escritos para especialistas, como no caso do estudo realizado por Cat (1998). Tudo isto justifica que seja não apenas válido, mas também indicado, tomar as idéias de Weinberg como base para a apresentação de uma corrente de pensamento dentro da física moderna, e de uma discussão filosófica a respeito da mesma.

Para cientistas como Weinberg, a busca da "Teoria de Tudo" representa a continuidade, e ponto culminante, de uma tendência histórica no sentido de chegar a te- orias que unifiquem as explicações que têm sido dadas para fenômenos aparentemente desconexos. Os avanços do passado, como a mecânica de Newton, que no final do século XVII explicou os movimentos celestes e terrestres com um mesmo conjunto de poucas leis, a síntese entre a eletricidade, o magnetismo e a óptica realizada por Maxwell no Século XIX, a unificação do espaço e tempo com a gravitação proposta por Einstein, e da química com a física atômica, através da mecânica quântica, são vistos como resultados daquele movimento (Weinberg 1999). No parágrafo de abertura de "Dreams of a Final Teory", Weinberg afirma:

"Este livro é sobre uma grande aventura intelectual, a busca das leis finais da natureza. O sonho de uma teoria final inspira muito dos atuais trabalhos em física de alta energia, e mesmo que não saibamos o que as leis finais podem ser ou quantos anos passarão antes que elas sejam descobertas, nas teorias de hoje nós acreditamos que estejamos a ver alguns lampejos dos contornos de uma teoria final.

A própria idéia de uma teoria final é controversa, e o assunto de um intenso debate correntemente. Essa controvérsia alcançou mesmo as salas das comissões do congresso americano; a física de altas energias se tornou cada vez mais cara, e suas demandas por apoio público se apoia em parte na sua missão histórica de desvelar as leis finais."(Weinberg 1993, pag. ix, ênfase adicionada)

O tom apaixonado do discurso pode ser melhor entendido ao se recordar que, na época em que o livro foi lançado, debatia-se no Congresso americano a construção de um superacelerador capaz de levar prótons a uma energia 20 vezes maior do que as máquinas existentes. É impossível fugir à impressão de que o livro, dirigido para o grande público, foi escrito com o objetivo de justificar e defender junto à opinião pública americana a despesa estimada em 8 bilhões de dólares ${ }^{1}$. Apesar da defesa de Weinberg, e de outros "pesos-pesados" como os nobelistas Leon Lederman e Sheldon Glashow, aquele Congresso barrou a construção do superacelerador $^{2}$.

Nos dias de hoje o ideal unificador é representado pelo que é conhecido como o Modelo Padrão ${ }^{3}$ para as partículas elementares e forças, que descreve com sucesso três das quatro forças conhecidas na natureza (força eletromagnética, força nuclear fraca e força nuclear forte). A força nuclear fraca, que atua nas interações envolvendo neutrinos como o caso do decaimento beta, foi unificada com o eletromagnetismo por meio da teoria das interações eletrofracas. O Modelo Padrão fornece uma descrição similar, ainda que separada, para a força nuclear forte que mantém os protons e nêutrons unidos nos núcleos atômicos e os quarks unidos no

\footnotetext{
${ }^{1}$ Quando questionado a respeito, em uma entrevista publicada no caderno Mais! da Folha de São Paulo, em 24/06/2001, Weinberg respondeu: “Eu estava tentando defender todo o programa de aprendizado sobre as leis da natureza, sobre os fundamentos da física. O supercolisor era o que jornalistas chamam de 'gancho', isto é, algo que havia aparecido recentemente no noticiário e eu abria uma oportunidade para discutir outras questões correlatas. A maior parte das coisas que eu discuto no livro não tem diretamente a ver com o supercolisor." Ainda reconhecendo que a última frase seja verdadeira, a resposta como um todo é pouco convincente. As discussões sobre o acelerador já eram matéria para o Congresso americano desde meados da década de 80 , e portanto não haviam aparecido "recentemente no noticiário". O que estava ocorrendo no início dos anos 90 (o livro foi publicado em 1993) era uma reversão de expectativas sobre a sua construção.

${ }^{2}$ Para uma estudo sobre os diversos motivos que levaram a esta decisão, ver Kevles (1995).

${ }^{3}$ Para uma apresentação didática do Modelo Padrão, ver Ostermann e Cavalcanti (1999)
} 
interior dos prótons e nêutrons (Weinberg 1999).

Como todo paradigma, o Modelo Padrão apresenta problemas para serem resolvidos pela comunidade de cientistas cujas pesquisas são guiadas pelo mesmo. No caso, o principal problema é o fato da força gravitacional não ter sido incluída no modelo, pois não se conseguiu, até o momento, conciliar os princípios das duas teorias fundamentais da física (a relatividade geral e a teoria quântica de campos) em uma nova teoria mais abrangente. Ao se tentar aplicar a teoria da relatividade geral, que dá conta da interação gravitacional, às partículas separadas por distâncias muito pequenas, nas quais a teoria quântica de campos é efetiva, inconsistências matemáticas são geradas revelando uma incompatibilidade entre as duas teorias. O problema acontece porque os campos da teoria da relatividade geral apresentam uma continuidade suave e, em dimensões muito pequenas (menores do que $10^{-33} \mathrm{~cm}=$ distância de Planck), as flutuações quânticas do tecido do espaço-tempo tornam-se enormes devido ao princípio da incerteza.

Uma outra ordem de problemas tem a ver com o fato de não se conseguir, ainda, deduzir constantes da natureza tais como as massas e as intensidades das unidades fundamentais de cargas elétricas das partículas elementares. Os valores utilizados para tais constantes nas equações do Modelo Padrão são aqueles que tornam as predições da teoria compatíveis com resultados experimentais; todavia, em uma teoria fundamental, o desejável é que as suas equações forneçam valores que possam ser verificados nas observações. Weinberg (2000) especula que, no fundo, os dois problemas são o mesmo e que a solução do problema mais fundamental, que é o da elaboração de uma teoria matemática consistente que incorpore a gravitação ao Modelo Padrão, mostrará também que os valores das constantes experimentais são o que são porque não poderiam ser diferentes, sem que a teoria perca a consistência matemática. Ele, assim como vários outros, acredita ainda que a Teoria das Supercordas apresenta-se como a melhor possibilidade no sentido da unificação da gravitação com as demais forças.

A idéia básica da Teoria das Supercordas é que as partículas fundamentais não são mais consideradas pontos geométricos mas sim cordas, de tamanho da ordem da distância de Planck, vibrando em onze dimensões. Diferentes padrões de vibração dariam as características das partículas como suas massas e cargas de forças. $\mathrm{O}$ fato das cordas terem um tamanho muito pequeno, porém finito, impõe a distância de Planck como um limite às distâncias que podem ser atingidas, ou mesmo ter existência no sentido convencional. Desta forma, as distâncias inferiores à de Planck, nas quais as flutuações quânticas tornam incompatíveis a mecânica quântica e relatividade geral, se desfazem, resolvendo o conflito entre as duas teorias ${ }^{4}$.

Os problemas com a Teoria das Supercordas têm se localizado, por um lado no alto grau de dificuldade e abstração do tratamento matemático necessário para a sua formulação e desenvolvimento (mesmo para uma ciência que se caracteriza pela matemática sofisticada e abstração conceitual), e por outro no seu pouco contato com a parte experimental. As soluções matemáticas com as quais a teoria trabalha, no momento, são aproximações de equações aproximadas, enquanto os níveis de energia previstos para as cordas se materializarem são tão altos que desafiam qualquer tentativa de uma observação experimental direta das mesmas. Mesmo no sentido de evidências menos diretas a teoria encontra-se muito à frente da parte experimental: os que trabalham com a teoria esperam que um acelerador em construção no CERN em Genebra (Large Hadron Collider), que deverá entrar em operação em 2010, venha a confirmar algumas previsões da teoria.

A questão é polêmica. Greene (2001) menciona que físicos de prestígio como Richard Feynman, Sheldon Glashow e Howard Georgi manifestaram-se contra a teoria no final dos anos 80 . Os dois últimos criticaram, naquela época, de forma particularmente agressiva, a falta de demonstrabilidade experimental da teoria, e o que viam como um desmesurado entusiasmo e não justificada supervalorização por parte dos seus proponentes. Mas devese acrescentar que, entrevistados quatro anos mais tarde por Greene, ambos revelaram um tom muito menos crítico com relação às supercordas (Greene 2001). Ele entende que o debate é alimentado, em parte, por questões de ordem filosófica: de um lado estariam os "tradicionalistas", para quem o trabalho teórico deve sempre estar próximo à observação experimental, e do outro os que acreditam ser possível teorizar sobre questões que estão fora das possibilidades atuais de experimentação.

A dimensão dos problemas teóricos e experimentais envolvidos na busca da teoria final são reconhecidos por Weinberg, que acredita que eles terão solução ainda que seja impossível precisar quando:

"É impossível dizer quando estes problemas serão solucionados. Eles podem ser resolvidos amanhã em um preprint remetido por um jovem teórico. Eles podem não estar ainda resolvidos em 2050, ou mesmo em 2150. Mas quando eles forem resolvidos, mesmo que não possamos fazer experimentos a 10 a $16 \mathrm{GeV}$ ou olhar em muitas dimensões, não teremos qualquer problemas em reconhecer a verdade da teoria fundamental unificada. O teste será se a teoria dá conta com sucesso dos valores medidos para as constantes do Modelo Padrão, além de quaisquer outros efeitos além do Modelo Padrão que possam ter sido descobertos até lá." (Weinberg 1999, pág. 43)

Para ele, a descoberta ${ }^{5}$ de uma teoria unificada permitirá responder a profundas questões cosmológicas relacionadas com as origens do universo mas não conduzirá, necessária e automaticamente, à compreensão de fenômenos menos fundamentais, mas de alta complexidade, como a tur-

\footnotetext{
${ }^{4}$ Uma excelente introdução à teoria das supercordas no nível de divulgação científica é o livro de Brian Greene (Greene 2001), que serviu de base para as considerações sobre a teoria feitas no presente artigo. Ver também Smolin (2002) para outra perspectiva sobre caminhos no sentido de uma superação dos conflitos entre a relatividade geral e a mecânica quântica.

${ }^{5}$ A palavra "descoberta" é adequada no caso pois Weinberg defende uma visão realista no que diz respeito ao "status" ontológico das teorias físicas.
} 
bulência das correntes oceânicas, o "folding" das moléculas de proteínas ou a supercondutividade em altas temperaturas. O que a teoria fornecerá, acredita Weinberg, são os princípios científicos fundamentais nos quais a compreensão de todos os fenômenos estaria baseada, mas cujos detalhes necessitariam ser trabalhados. Sugere ainda que, no caso de problemas como a cura do câncer ou compreensão da consciência humana, toda a física necessária para a solução já é provavelmente conhecida (Weinberg 2000, pág. 51).

A idéia de que as aplicações práticas de uma teoria fundamental unificada serão muito limitadas, e não terão efeitos sensíveis em nossa vida cotidiana, foi também manifestada pelo físico holandês Gerard 't Hooft, que recebeu o Prêmio Nobel de Física de 1999 por seus trabalhos sobre renormalização. Ele acredita que uma teoria de tal tipo seja possível em princípio, mas que ela não nos capacitará a explicar qualquer coisa que queiramos, devido à natureza complexa de muitos dos fenômenos, e considera que a expressão Teoria de Tudo não deve ser interpretada de forma absoluta. Afirma ainda que teria sido melhor se em seu lugar se tivesse utilizado "Lei Última" ou "Lei Básica", a qual seria subjacente a todas as partículas e forças que constituem o universo, e que a descoberta de tal lei seria uma grande conquista, mas adverte:

"A Teoria de Tudo do tipo que estamos discutindo aqui nunca será uma teoria de tudo no sentido literal. O comportamento caótico nos impedirá de computar "tudo que quisermos conhecer" já a partir de um estágio muito inicial. A questão que estamos tratando é a questão se existe ou não uma lei final e se seremos capazes de descobri-la. A questão não é se seremos capazes de usar essa lei para explicar qualquer coisa que gostaríamos de ter explicado. Quase certamente, nossa leis dinâmicas serão inúteis para isto, devido à tremenda quantidade de complexidade, presumivelmente já em escalas um pouco maiores do que a escala de Planck." ("t Hooft 1994, pag. 32)

Assim como Weinberg, 't Hooft é um realista para quem a natureza produz um modelo matemático, ao qual chamamos de nosso universo atual, que pode ser descoberto. Comentando sobre a possibilidade de que isso seja efetivamente conseguido ele refere-se, inicialmente, ao fato de que, no passado, físicos já acreditaram que as leis últimas do mundo estivessem muito próximas de serem encontradas e no entanto estavam errados. O que não significa para ele, todavia, que daí se possa extrair lições de forma imediata, visto que o fato de que a crença tenha sido prematura no passado não implica que também venha a sê-lo no futuro. Também concorda com o cientista americano a respeito do fato de que a solução virá por meio de considerações de ordem teórica e engenhosidade matemática mas, de forma bem mais enfática, chama atenção para os problemas a serem enfrentados na busca. A razão para isso é que, diferentemente de Weinberg, 't Hooft não acredita que a Teoria de Supercordas seja uma boa aposta no sentido de teoria final e para ele, também em desacordo com Weinberg, o caminho passa por questões ligadas à interpretação da mecânica quântica.

A postura realista de 't Hooft e sua crença na possibilidade de chegarmos a uma teoria final não são suficientes, no entanto, para faze-lo deixar de perceber que a própria crença é derivada de um pressuposto não passível de demonstração:

"É com a nossa engenhosidade humana que estou contando. Definitivamente eu acredito que idéias inteligentes serão encontradas nos permitindo deduzir como a Natureza funciona. Se uma lei fundamental existe, ela será encontrada, mais cedo ou mais tarde. Se a lei for encontrada, seremos capazes de reconhecê-la como sendo muito provavelmente a verdade. Não tenho dúvida quanto a isso. Também não tenho dúvida de que, não importa quão convincente a evidência para a nova super-teoria venha a ser, questões $e$ objeções continuarão a ser levantadas. Não existirá nunca uma prova definitiva para a teoria definitiva." ("t Hooft 1994, pág. 30, ênfase adicionada)

Um ponto importante a ser destacado é que a crença na possibilidade de uma teoria fundamental unificada vem geralmente acompanhada da crença de que esta será uma Teoria Final, ou seja, uma teoria definitiva, como fica claro em Weinberg:

"É possivel que quando tenhamos finalmente compreendido como partículas e forças se comportam em energias da ordem de 10 a $18 \mathrm{GeV}$, encontremos novos mistérios, com uma unificação final tão longe como nunca esteve. Mas eu duvido. Não existem indicações de qualquer escala de energia fundamental acima além de 10 a $18 \mathrm{GeV}$, e a teoria de cordas sugere mesmo que energias mais altas não têm sentido.” (Weinberg 1999, pág. 43)

Ainda que as idéias de uma Teoria Final e uma Teoria de Tudo estejam bastante associadas no pensamento de Weinberg, elas não estão logicamente ligadas. É possível se admitir uma Teoria de Tudo que não seja uma Teoria Final (podemos pensar na possibilidade de se chegar a outra Teoria de Tudo radicalmente diferente) ou uma Teoria Final que não seja uma Teoria de Tudo (que seja impossível, por exemplo, avançar além de certo ponto no conhecimento, sem que se tenha chegado a uma teoria fundamental unificada). No caso de Weinberg, todavia, a crença na associação entre as duas teorias tem a ver com duas características epistemológicas do seu pensamento: o realismo e o reducionismo.

O realismo de Weinberg não se refere apenas a uma crença na existência de coisas diretamente observáveis, mas na realidade das leis naturais. Para ele tais leis são verdades a serem descobertas e das quais a ciência nos aproxima cada vez mais, chegando a qualificar o desvelamento das mesmas como uma "missão histórica". Tal postura é bastante consistente com a crença de que é possível chegar a uma lei definitiva, diferentemente de quem acredita que as leis, e teorias em geral, são construções que tentam dar conta dos fenômenos observados da melhor maneira possível, em um determinado momento histórico ${ }^{6}$. Quanto ao reducionismo, sua posição pode ser resumida com o ponto de vista expresso no início de um capítulo (“Two Cheers for Reductionism”):

\footnotetext{
${ }^{6}$ Weinberg se manifesta fortemente contra os positivistas, os anti-realistas e os construtivistas sociais no Capítulo Sete de "Dreams of Final Theory", cujo título "Against Philosophy” é revelador.
} 
“... o ponto comum em todas as idéias do reducionismo é um senso de hierarquia, que algumas verdades são menos fundamentais do que outras às quais elas podem reduzidas, como a química pode ser reduzida à física." (Weinberg 1993, pág. 40)

No topo da hierarquia se encontraria a física de partículas. Isto não significa, segundo Weinberg, que as outras ciências poderiam vir, na prática, a perder sua autonomia sendo absorvidas pela física de partículas elementares, ou que progressos nas outras ciências dependeriam de progressos na física de partículas (Cat 1998). Ele também afirma não acreditar que os problemas da física das partículas sejam os únicos interessantes e profundos da ciência ou da física, ou que os químicos devem se dedicar apenas a resolver equações da mecânica quântica para várias moléculas, ou que os biólogos devem parar de pensar em plantas e animais como um todo e se dedicar apenas a células e DNA. Ao mesmo tempo, porém, não deixa de frisar que existe uma ordem lógica na natureza de acordo com a qual ramos da física, como a termodinâmica, e outras ciências, como a biologia e a química, podem ser consideradas como repousando nas leis mais profundas da física das partículas elementares (Weinberg 1993):

"Para mim, o reducionismo não é um guia para programas de pesquisas, mas uma atitude frente à própria natureza. Não é nada mais ou menos do que a percepção que princípios científicos são o que são por causa de princípios mais profundos (e, em alguns casos, acidentes históricos) $e$ que todos estes princípios podem ser traçados a um conjunto de leis simples e conectado. Nesse momento na história da ciência parece que o melhor jeito de nos acercarmos destas leis é através da física das partículas elementares, mas este é um aspecto acidental do reducionismo e pode mudar. ....... A visão de mundo reducionista é fria e impessoal. Ela deve ser aceita como ela é, não porque gostemos dela, mas porque é a forma como a natureza é." (Weinberg 1993, pag. 41)

Note-se que Weinberg usa o termo visão de mundo para referir-se ao reducionismo. Trata-se, independente da certeza com que ele assume sua perspectiva, de um "tema do pensamento científico", no sentido discutido por Holton $(1973,1979)$ : uma pressuposição que influencia fortemente a direção do trabalho científico mas cuja justificativa encontra-se fora do âmbito da própria ciência, ou pelo menos não segue os padrões de cientificidade das ciências naturais, estando mais enquadrada nas discussões de ordem filosófica ${ }^{7}$. O mesmo pode ser afirmado com relação à crença na possibilidade de uma teoria final unificada.

Weinberg (1993) chama atenção para o fato de que os físicos de partículas são particularmente sujeitos a serem considerados reducionistas, o que teria azedado as relações entre eles e cientistas para as quais aquela visão não representa um ideal muito popular. Aqui ele está se referindo tanto a divergências entre membros da comunidade da física e de outras ciências, principalmente de partes da biologia (os quais relutariam em aceitar que seu conhecimento repousa, em última análise, nas leis mais profundas da física), como a tensões entre os próprios físicos ${ }^{8}$.

Ao lado de Weinberg no compartilhamento da visão de mundo reducionista podem ser encontrados expoentes da física, como Vicktor Weisskopf, Leon Lederman, Robert Wilson, Abdus Salam, e Sheldon Glashow, enquanto no campo oposto figuram físicos importantes como Philip Anderson (ganhador do Prêmio Nobel em 1977, por trabalhos sobre supercondutividade), James Krumhansl, Leon Kadanoff, Kenneth Wilson, e um biólogo do quilate de Ernst Mayr (Cat 1998). Não é objetivo deste trabalho entrar nas nuances das duas posições no nível de detalhes com que são tratadas no artigo de Cat, mas dar uma idéia do eixo principal pelo qual passa o debate.

Assim como a visão reducionista foi caracterizada a partir do ponto de vista de Steven Weinberg, a postura antireducionista pode ser personificada em Philip Anderson ${ }^{9}$. Seu texto "More is different", considerado por muitos como um manifesto anti-reducionista, foi publicado na revista Science em 1972. Nele são cristalizadas respostas que Anderson havia dado anteriormente a pontos de vista expressados por Wicktor Weisskopf, que era diretor do CERN. Defendendo o financiamento para grandes aceleradores de partículas, este último considerava que todas as ciências seriam em última análise um ramo da física, e que haveria uma divisão entre as pesquisas em física de altas energias e uma boa parte da física nuclear, dirigidas para as leis fundamentais, e as pesquisas em física de estado sólido, plasma e talvez a biologia que teriam por objetivo explicar os fenômenos a partir das leis fundamentais conhecidas (Cat 1998).

Contra este ponto de vista Anderson argumentou que:

"A hipótese reducionista não implica, de forma alguma, em uma 'construcionista': a habilidade de reduzir tudo a simples leis fundamentais não implica na habilidade de começar daquelas leis e reconstruir o universo. De fato, quanto mais os físicos de partículas elementares nos dizem a respeito das leis fundamentais, menos relevância elas parecem ter para os problemas reais do resto da ciência, muito menos ainda para aqueles da sociedade...o comportamento de grandes e complexos agregados de partículas elementares, como se constata, não é possível de ser entendido em termos da simples extrapolação das propriedades de poucas partículas. Pelo contrário, em cada nível de complexidade propriedades inteiramente novas aparecem, e a compreensão dos novos comportamentos requer pesquisa que

\footnotetext{
${ }^{7}$ Noção semelhante aos componentes metafísicos dos paradigmas (Kuhn 1975) ou às imagens de natureza discutidas em Abrantes (1998).

${ }^{8}$ Kevles (1995) aponta que as tensões internas à comunidade dos físicos contraporiam, de um lado físicos da área de partículas e altas energias e de outro os da área de matéria condensada. Segundo ele existiria uma tendência entre os físicos de partículas a considerarem o trabalho dos físicos de matéria condensada como sendo intelectualmente de segunda classe: enquanto os primeiros buscariam, de forma mais profunda, as leis e os constituintes fundamentais do universo, os outros lidariam com as leis que governam a matéria como ela existe em agregados encontrados ou produzidos pelo homem.

${ }^{9}$ A oposição entre Anderson e Weinberg transcendeu a divergência filosófica acadêmica. Nos debates sobre a construção do superacelerador no Congresso americano, Anderson foi o físico com maiores qualificações (Prêmio Nobel) a se manifestar contra.
} 
eu considero tão fundamental em sua natureza quanto qualquer outra.” (Anderson 1972, citado por Cat 1998).

Segundo ele, a relação entre os sistemas e suas partes constitui-se, do ponto de vista do conhecimento, em uma via de mão única. As leis de sistemas complexos obedecem às leis que regem os seus sub-sistemas constituintes, e neste sentido a análise não é só possível mas frutífera; por outro lado, ao se passar de um sistema mais simples para um mais complexo novas propriedades aparecem, e estas não seriam decorrentes apenas das propriedades dos subsistemas, o que tornaria a síntese construtiva impossível. Em cada estágio, novas leis, conceitos e generalizações tornam-se necessárias (daí o título do artigo "Mais é diferente"). Anderson acredita que as leis próprias dos níveis mais complexos não contradizem as leis das partículas elementares, mas não podem ser consideradas menos fundamentais. O aparecimento de características novas em conjuntos, que não podem ser deduzidas do conhecimento das suas partes, consideradas em separado ou em combinações parciais, tem sido designado pelo termo emergência (Mayr 1998) ${ }^{10}$.

Como exemplos de propriedades emergentes Anderson apresenta o caso da molécula de amônia cujo comportamento não pode ser, acredita ele, predito a partir das leis fundamentais da mecânica quântica. Seu argumento é de que, em geral, o estado de um sistema apresenta assimetrias que não podem ser derivadas das leis fundamentais que são simétricas. O mesmo argumento seria aplicável nos casos das estruturas macroscópicas cristalinas, supercondutividade, transições de fase, e nos casos de sistemas de mais complexos da química, biologia e mesmo das ciências humanas (Cat 1998).

É importante salientar que, para os defensores da emergência, a complexidade em um sistema não deve confundida com o sistema ser complicado, mas implica em um comportamento de grande diversidade e surpreendente, que dá lugar a uma estrutura com propriedades de caráter inesperado que não preexistem nos componentes do sistema. Casos extremos seriam a emergência da consciência e da vida, mas o mesmo processo aconteceria em sistemas puramente físicos como os estudados pela termodinâmica e mecânica estatística longe do equilíbrio, com o surgimento de padrões ordenados, através de uma evolução auto-organizada, em uma escala macroscópica. Estes estados ordenados autoorganizados acontecem somente em sistemas abertos, longe da situação de equilíbrio e sujeitos a uma evolução não linear. Para muitos, trata-se de um novo paradigma que, entre outras coisas, poderia vir a esclarecer aspectos que ligam os processos físicos aos biológicos ${ }^{11}$

Weinberg procurou responder aos argumentos emergentistas. Com relação às crítica do biólogo Ernst Mayr ele afirma que o mesmo não entendeu a diferença que ele faz entre:

“...reducionismo como uma prescrição geral para o pro- gresso na ciência, que não é o meu ponto de vista, e reducionismo como uma afirmação de ordem na natureza, que eu penso ser simplesmente verdadeira. Mayr e eu ainda mantemos boas relações mas desistimos de tentar converter um ao outro." (Weinberg 1993, pg.42)

Note-se, em primeiro lugar, a sua postura de distanciarse do reducionismo eliminativo, segundo o qual as outras ciências tenderiam a perder a sua autonomia sendo absorvidas pela física de partículas (Cat 1998). Ele reconhece a emergência de novos fenômenos próprios em níveis de maior complexidade e que não apresentam equivalentes nos níveis menos complexos. Como exemplos ele menciona o fato de não haver inteligência no nível das células individuais, nem vida no nível atômico e molecular. No caso da física ele cita a termodinâmica, que trabalha com conceitos emergentes como temperatura e entropia, que perdem sentido no nível das partículas individuais. Apesar disto, a termodinâmica apresenta-se para Weinberg (1993, pág. 2933) como um exemplo clássico de reducionismo teórico pois foi explicada em termos de partículas e forças através da mecânica estatística. Todavia, vale a pena notar que nesta discussão ele não menciona os estudos de Prigogine (Prigogine and Stengers 1984) sobre a termodinâmica e mecânica estatística fora de equilíbrio, que têm servido de base para defesas de posições emergentistas (ver nota 11).

Weinberg aceita a noção de emergência enquanto conveniência prática de que, em diferentes níveis de experiência, a descrição e análise sejam feitas em termos diferentes, mas nega isto implique na existência de outros tipos de leis fundamentais.

O que Weinberg parece não se dar conta é que para Mayr a sua idéia de reducionismo não é "simplesmente verdadeira", não sendo de estranhar que tenham desistido de discutir o assunto. Como conseqüência, apesar de ambos rejeitarem o reducionismo eliminativo, a noção de emergência é mais radical em Mayr (e Anderson), para quem ela significa a negação da possibilidade da relação de "seguimento" de um nível dito mais fundamental para outro mais complexo, sendo que princípios de ligação são requeridos para conectar conceitos e leis dos níveis diferentes (Cat 1998).

Quanto à oposição dos físicos, principalmente da matéria condensada, ele procura chamar a atenção para motivações relacionadas com disputas por verbas de pesquisa e por ressentimentos, não abrindo mão, todavia, de considerar a área de partículas elementares como essencialmente mais fundamental:

"Mais sério para o planejamento de pesquisas na nação tem sido a oposição ao reducionismo dentro da própria física. As pretensões dos físicos de partículas aborrecer profundamente físicos que trabalham em outros campos, como a física da matéria condensada, que se sentem em competição por verbas com os físicos de partículas elementares.” (Weinberg 1993, pag. 42)

\footnotetext{
${ }^{10}$ O segundo capítulo do livro de Mayr traz uma discussão do assunto do ponto de vista da biologia. Ver também El-Hani e Pereira (1999) e El-Hani (no prelo) para uma discussão interessante sobre o tema.

${ }^{11}$ Estas posições foram extraídas de Luzzi (2000) que apresenta uma defesa da tese emergentista, baseada principalmente nos trabalhos de Ilya Prigogine (Prêmio Nobel de Química em 1977) e sua escola.
} 
E, referindo ao debate a respeito da construção do superacelerador:

"Um dos membros do painel (de defesa da construção) argumentou que não deveríamos dar a impressão de que pensamos que a física das partículas elementares seja mais fundamental do que outros campos, porque isto tendia a enraivecer nossos colegas em outras áreas da física.

A razão pela qual nos damos a impressão de que pensamos que a física das partículas elementares seja mais fundamental do que outros campos da física é porque ela é. Eu não sei como defender a quantia gasta em física de partículas sem ser franco sobre isto. Mas sobre a física de partículas elementares ser mais fundamental eu não quero dizer que ela é matematicamente mais profunda ou que ela seja mais necessária para progressos em outros campos ou qualquer outra coisa, mas somente que ela está mais próxima do ponto de convergência de todas nossas setas de explicação." (Weinberg 1993, pag. 43, ênfase adicionada)

Weinberg usa como exemplo o estudo da supercondutividade de certos compostos de cobre, oxigênio e outros elementos exóticos, em temperaturas muito mais altas do que se pensava possível, em que Anderson e outros físicos da matéria condensada estão envolvidos, para compará-lo com as pesquisas dos físicos de partículas que estão tentando entender a origem das massas dos quarks, elétrons e outras partículas do Modelo Padrão. Mesmo reconhecendo que, muito provavelmente, os físicos das duas áreas irão resolver seus problemas sem a ajuda um dos outros ele aproveita para ressaltar, novamente, o caráter mais fundamental de sua área:

"A diferença entre estes dois problemas é que, quando os físicos da matéria condensada finalmente conseguirem explicar a supercondutividade de alta temperatura - não importa que idéias brilhantes eles tiverem inventado no caminho - no final a explicação terá a forma de uma demonstração matemática que deduz a existência deste fenômeno das propriedades conhecidas de elétrons, fotons e núcleos atômicos; em contraste quando os físicos de particulas elementares finalmente entenderem a origem da massa no Modelo Padrão a explicação estará baseada em aspectos do Modelo Padrão dos quais estamos incertos hoje em dia, e que não poderemos aprender (ainda que possamos adivinhar) sem novos dados de equipamentos como Supercolisor. A física de partículas elementares portanto representa uma fronteira no nosso conhecimento de uma forma em que a física da matéria condensada não representa." (Weinberg 1993, pag. 46, ênfase adicionada)

A afirmação acima foi feita no contexto da defesa da construção do superacelerador e pode soar como peça retórica, não deixando porém de refletir a crença no caráter "unicamente fundamental do seu trabalho". Mas Weinberg vai mais longe, ao pretender que por isso o reducionismo tenha um valor corretivo, agindo não apenas como um modelo descritivo, mas prescritivo para a atividade científica em geral. Assim, ele propõe que:

"Nós não daremos muita atenção a uma proposta lei autônoma da macroeconomia se ela não puder ser expli- cada em termos do comportamento de indivíduos oи a uma hipótese sobre supercondutividade que não possa ser explicada em termos de elétrons e fótons e núcleos. A atitude reducionista provê um filtro útil que salva cientistas em todos os campos de perder seu tempo em idéias que não valem ser perseguidas. Neste sentido, somos todos reducionistas agora." (Weinberg 1993, pag. 50)

A citação acima constitui-se em mais uma instância do estilo de pensamento reducionista em ação. O que parece óbvio para Weinberg certamente não seria aceitável para físicos com uma visão emergentista, já que, para os últimos, a supercondutividade não poderia ser explicada apenas através das propriedades que regem o comportamento de eletrons, fótons e núcleos quando não interagindo em sistemas complexos. Por razões deste tipo é que pode-se concordar com Cat quando, ainda que reconhecendo o reducionismo de Weinberg como um ideal de unificação com uma longa tradição na ciência, aponta, de forma crítica, que:

"Ele repousa nas pressuposições de que toda teoria científica aceita foi ou será reduzida e que na ausência de tal critério todas as teorias permanecem soltas e com credibilidade científica não conferida. Mas as duas pressuposições não são inatingiveis. A primeira, ainda que de reconhecido valor heurístico na história da criatividade científica, é nesse contexto não realista, e passa por cima dos argumentos da emergência. A segunda abraça uma forma de metodologia que não tem lugar na prática científica." (Cat 1998, pág. 299)

\section{Opiniões da comunidade}

\section{III.1 Objetivo e metodologia}

Os resultados ora apresentados fazem parte de uma pesquisa empírica mais ampla que teve por objetivo investigar a opinião de membros da comunidade de físicos do Brasil a respeito dos temas: fim da ciência, no sentido proposto por Horgan (1998); teoria final, unificação e reducionismo; conhecimento científico e realidade; a suspensão da construção do "superconducting supercollider" pelo Congresso americano. Neste artigo encontram-se apresentados os resultados referentes aos temas teoria final, unificação e reducionismo.

A comunidade investigada consistiu no conjunto de sócios da Sociedade Brasileira de Física listados no seu Diretório 1999-2000. Ainda que nem todos os membros da comunidade de físicos brasileiros estejam na listagem, é bastante razoável se supor que uma parcela bastante representativa faça parte da mesma. O diretório traz informações mais detalhadas sobre 1085 dos aproximadamente 5900 sócios listados, o que permitiu que a coleta de dados fosse feita por correio eletrônico. Dos 1085 nomes com informações que constam do Diretório, 91 ou não tinham endereço eletrônico, ou o mesmo estava errado (caso em que o "e-mail" retornou com mensagem de erro de endereço).

Assim, pode-se assumir que 994 mensagens chegaram ao seu destino, das quais 144 foram respondidos, o que cor- 
responde a uma taxa de retorno de $15 \%$. Este valor encontrase dentro dos padrões de retorno em pesquisas que utilizam meios convencionais como, por exemplo, questionários em papel enviados pelo correio. Foram analisadas também, e incluídas na amostra, as respostas de cinco professores e três alunos de doutorado da UFSC, que participaram da fase de teste do instrumento de pesquisa, totalizando 152 pessoas. A coleta de dados foi realizada durante o ano 2000 (fase de teste no primeiro semestre, e coleta principal no segundo semestre).

O levantamento das opiniões foi realizado através de um instrumento composto por um conjunto de sete textos curtos expressando pontos de vistas sobre os temas investigados (Anexo I). Para cada texto o participante deveria expressar o seu grau de concordância e comentar os motivos que levaram à sua apreciação. Os Textos 4, 5 e 7 referem-se aos temas tratados neste artigo, e apenas as respostas aos mesmos são aqui analisadas.

No Anexo II estão resumidas outras características do grupo que participou do levantamento de opiniões.

\section{III.2 Resultados}

As idéias expressando a crença em uma teoria final unificada e na visão reducionista hierárquica aparecem nos Textos 4 e 5. Já o Texto 7 assume uma posição oposta à possibilidade de uma teoria final na física.

\section{III.2.1 Respostas ao texto 4}

\section{Respostas MD (Muito em Desacordo) e D (em Desa- cordo)}

Dos 152 participantes, 48 mostraram-se MD e $53 \mathrm{em}$ $\mathrm{D}$ com o texto, o que indica uma tendência (66\%) de rejeição. Dos 48 que rejeitaram mais fortemente (MD), 20 não apresentaram comentários, fizeram comentários triviais, ou ainda os argumentos eram de difícil compreensão; o mesmo ocorreu com 26 que responderam D. Dentre os que apresentaram comentários mais relevantes, em geral foi impossível distinguir as razões que levaram alguns a responderam MD e outros $\mathrm{D}$, visto que os comentários eram de natureza semelhante.

23 dos participantes que responderam MD ou D centraram a suas discordâncias na questão da hierarquia e na crítica ao reducionismo. Por exemplo:

Nível de concordância: $M D$

Comentários: Acredito que nunca chegaremos a uma teoria final do que quer que seja. Também não creio que haja uma ciência fundamental, mais importante, hierarquicamente mais básica que as outras. Posso entender e aceitar que haja ciências que nasceram antes e que tenham como o seus objetos de estudo sejam mais simples, por isso a descrição deles é mais precisa e controlada. A Física é uma destas ciências e por isso é um paradigma da atividade científica. Agora, não entendo que se hierarquizem os conhecimentos pelo assunto, pela complexidade ou pela teia de relações. (DUD-NUC/TEOR) 12

\section{Nivel de concordância: $M D$}

Comentários:De nada servirá essa teoria fundamental. Cada nível da hierarquia tem suas próprias leis - propriedades emergentes - que não podem ser entendidas através do estudo do nível inferior. (FOF-EST/TEOR)

Nivel de concordância: $D$

Comentários: Esta filosofia reducionista mostrou-se falsa à luz da história. Com a teoria (já simplificada) de Dirac mal conseguimos descrever com precisão o átomo mais simples (o hidrogênio). Para átomos de muitos elétrons e mais ainda para moléculas, é indispensável fazer aproximações. Estas aproximações estão geralmente baseadas nos conhecimentos da ciência "menos básica" (por exemplo a teoria da valência, de Pauling, na Química Quântica - ou Física Molecular -). Naturalmente, um bom conhecimento da ciência "mais básica" é muito importante. Mas não podemos dizer que a Química seja "uma das aplicações da Física”. (MAS -FMC / TEOR)

Em geral, as críticas ao reducionismo hierárquico vinham acompanhadas de discordâncias com a possibilidade de uma teoria final. Apenas 06 dos 23 admitiram, em tese, a possibilidade de uma teoria final, discordando porém do reducionismo hierárquico. Como todos os 06 responderam $\mathrm{D}$, pode ter sido esta a razão por não terem respondido MD. A resposta mais elaborada nessa direção veio de um físico das áreas de cosmologia e partículas e campos:

\section{Nível de concordância: $D$}

Comentários: Apesar de achar que se houver uma teoria final da Física esta seria a explicação última para todos os fenômenos, não creio que isso justifique uma hierarquia clara entre os diferentes ramos científicos. Ao menos no sentido com que o termo hierarquia é usualmente empregado, significando uma "superioridade" intrínseca de um ramo da Ciência sobre outro. Não dá para estudar a Química como mera Mecânica Quântica aplicada aos átomos e moléculas pois o problema seria intratável. Nem estudar Biologia como Química aplicada, pelo mesmo motivo. A lei fundamental explica por que alguns fenômenos são possíveis e outros não, e como os fenômenos se desenvolvem. Mas não parecem ser capazes de explicar por que alguns fenômenos se organizam da forma como o fazem. Por exemplo, a Mecânica Quântica explica por que os aspectos básicos da Química funcionam e esta por sua vez explica como a Vida, da forma como conhecemos, é possível. Mas se não houvesse Vida tanto a Química quanto a Mecânica Quântica continuariam válidas. Portanto estas explicam por que a Vida pode existir mas não por que ela existe! Não creio que a descoberta da teoria final da Física irá mudar essa situação. Isso implica que a Biologia desempenha um papel fundamental para o nosso entendimento de por que o mundo é como o vemos, sendo portanto muito questionável estabelecer hierarquias. Sempre podemos argumentar que a teoria básica é tal que a configuração do que vemos no

\footnotetext{
${ }^{12}$ As três primeiras letras são um símbolo (não as iniciais do nome) para o autor do comentário e as outras identificam a(s) área (s) de atuação segundo a tabela que aparece no Anexo II. As citações foram copiadas dos arquivos enviados como respostas, daí eventuais erros de linguagem.
} 
mundo é a única possível, mesmo que não possamos visualizar isso devido à complexidade que nos cerca. Portanto a teoria final da Física explicaria por que a vida existe, mesmo que não fôssemos capaz de saber exatamente como. Mas mesmo isso não muda o fato de que é a Biologia que, provavelmente, poderá nos responder a pergunta sobre por que a Vida existe. Por isso acho questionável tentar estabelecer uma hierarquia entre os ramos da Ciência. Parece-me haver uma certa dose da arrogância típica dos Físicos por detrás disso. (TRS - COS,FPC / TEOR)

17 das respostas MD ou D fizeram referência ao fato de que existem outras ciências não explicadas pela física ou de que natureza é muito complexa para ser conhecida de forma final. 06 participantes que responderam D demonstraram uma crença na hierarquia mas não na possibilidade de uma teoria final. Isto também explicaria a escolha de D e não de MD. Por exemplo:

Nivel de concordância: $D$

Comentários: A ciência tem um hierarquia sim. Existem as teorias fundamentais, a partir das quais podemos deduzir outros fenômenos a partir de "primeiros princípios". Por exemplo, a partir da teoria da relatividade geral podemos deduzir a hidrodinâmica newtoniana e depois aplicá-la a fenômenos de turbulência, etc. . No entanto essa hierarquia não implica na existência de uma "teoria do todo", ou "teoria final", ou ainda Mother ou Father theory, como alguns físicos chamam as teorias de cordas. Para mim não está claro que um dia chegaremos à teoria final. Podem sempre sobrar ilhas que faltam unificar. Ou ainda chegarmos a uma teoria completa, e depois descobrirmos novos fenômenos que ela não consegue explicar. Não vejo nenhuma razão para acreditar que deva existir uma teoria final. A natureza é, como ela é. Se o Homem um dia vai poder resumi-la a um conjunto fechado de axiomas, isso não está nada claro. Pode inclusive haver um limite técnico, a partir do qual não se possa explorar um determinado espectro de energia $e$ nunca saber qual a física desse setor. A única motivação que vejo para estar convencido da existência de uma teoria final é teológica. (MAM-COS / TEOR)

Outras respostas MD e D apresentaram comentários envolvendo as limitações do nosso cérebro (04), visão antirealista da ciência (03), e impossibilidade saber se chegamos a uma teoria final (02).

\section{Respostas MA (Muito de Acordo) e A (de acordo)}

06 dos participantes responderam MA e 21 A, totalizando $18 \%$ dos participantes, o que indica uma baixa aceitação das idéias contidas no Texto 4. 06 respostas MA e 14 A não apresentavam comentários, ou tinham comentários triviais ou de difícil entendimento.

Dos 07 comentários MA e A relevantes, 04 respostas destacaram o caráter fundamental e mais avançado da física. Por exemplo:

Nível de concordância: $A$
Comentários: Acredito que a Física é ainda a ciência mais avançada que existe e se ela tem a possibilidade de ser o alicerce para outros conhecimentos, justifica-se a procura de uma teoria final (MUS - OPT / EXP)

Uma resposta A aceitava a hierarquia mas a não a idéia de uma teoria final. Este participante apresentou um ponto de vista coincidente com outros 06 mencionados acima que responderam $\mathrm{D}$ pelos mesmos motivos.

Nível de concordância: A

Comentário: Concordo com o aspecto de que a ciência tem uma hierarquia, e quanto a possibilidade de uma teoria geral. Mas não gosto de chamá-la de "final”. Mesmo uma teoria de abrangência geral pode ser substituida por outra melhor, em princípio. (ZLF - PLA / TEOR)

Um dos participantes que respondeu A comentou que a teoria final será provavelmente a de supercordas ${ }^{13}$, porém fazendo uma ressalva, que deve ter sido o motivo para não ter respondido MA:

Nivel de concordância: A

Comentários: Provavelmente a teoria final da física, no sentido descrito acima, é a teoria de supercordas. Entretanto, sempre vai restar uma pontinha de dúvida se ela não seria uma teoria efetiva de outra teoria ainda mais fundamental. Só poderemos responder a essa questão no dia em que compreendermos todos os aspectos da teoria de supercordas. (RLO - FPC,COS / TEOR)

E outro comentou que a teoria final estará sempre sendo aperfeiçoada.

\section{Respostas I (Indiferente)}

Dos 24 participantes (16\% do total) que responderam I, 13 não apresentaram comentários, ou afirmaram não terem condições de opinar sobre o tema, ou ainda tinham comentários de difícil entendimento e/ou triviais ou não pertinentes.

Dentre os 11 que apresentaram comentários relevantes 06 participantes comentaram existir outras ciências ou outras formas de conhecimento envolvendo fenômenos específicos e complexos, não redutíveis a uma teoria final da física. Não há como estabelecer a razão pela qual estes participantes optaram pela resposta I e não por MD e D, associadas com o mesmo argumento. Uma hipótese seria que a resposta I indicaria indiferença ou desconhecimento como aparece no exemplo abaixo:

Nivel de concordância: I

Comentários: Essa linha de raciocínio depende de quão eficiente pode ser o reducionismo. Reduzir a psicologia à biologia - à química - à física é algo que tenho ouvido falar, mas não conheço o suficiente para entender os seus fundamentos. Redução da química à física é algo conhecido e possivel, sob diversos aspectos. Entretanto, organismos

\footnotetext{
${ }^{13} \mathrm{O}$ número de referências à Teoria da Supercordas nas repostas aos Textos 4 e 5 foi relativamente pequeno. Além da resposta transcrita um outro participante que respondeu MA aos Texto 4 e 5 se referiu à teoria. Outras cinco menções que apareceram foram de pessoas que responderam MD e D aos textos ora analisados.
} 
vivos, fora do equilíbrio termodinâmico e vivendo em estado de neg-entropia é algo que não conheço bem e não me sinto à vontade para opinar. O que vejo é que, com o estudo e a melhor compreensão de fenômenos não lineares, uma hierarquia diferente pode ser pensada, mas tenho dúvidas quanto à sua efetivação. Principalmente se for exigido que seja uma teoria "Física". (SOA - AST,ENS / TEOR))

Um participante comentou ainda estarmos longe da teoria final e discordou do que considerou o tom arrogante do texto. Trata-se claramente de um caso de rejeição das idéias do texto, que comportaria melhor uma resposta MD.

E quatro outros comentaram que o texto não tinha lógica, ou que as afirmativas exigem maiores reflexões.

\section{III.2.2 Respostas ao texto 5}

\section{Respostas MD e D}

$21(14 \%)$ dos participantes responderam estar MD e 59 (39\%) responderam D, totalizando $53 \%$ do total de participantes. Dos que responderam MD, 09 ou não apresentaram comentários, ou fizeram comentários que pouco acrescentam ao texto, ou ainda se referiram a comentários feitos ao Texto 4. O mesmo ocorreu com 28 dos que responderam D.

Dentre os demais, um dos participantes respondeu MD por não acreditar que a unificação irá necessariamente acontecer:

Nivel de concordância: $M D$

Comentários: Isso é o que eu chamo de "wishful thinking”. Essas duas teorias podem ser unificadas, mas podem não ser. Somente saberemos acerca dessas conseqüencias DEPOIS de uma possível unificação, que pode nunca ocorrer. E se essas duas teorias forem definitivamente incompatíveis? Não podemos adiantar as conseqüências sem antes obter os resultados. Toda essa "previsão" acerca de solução de problemas é absolutamente inconclusiva. É como caçar OVNI's. Eles podem existir, mas também podem não existir. Se nada podemos concluir, melhor irmos fazer alguma outra coisa (ou ir p/ a praia). (RMA COS,AST/TEOR)

Outros três comentaram no sentido de que a ciência não tem fim.

Três que responderam MD comentaram que uma teoria unificada é possível, mas não seria uma teoria final. Estas respostas estão próximas de algumas respostas D e A. Um dos comentários neste sentido foi um dos poucos a fazer referência explicita à Teoria das Supercordas, sem no entanto acreditar que ela venha a ser uma teoria final:

Nivel de concordância: $M D$

Comentários: Tenho certeza que quando alguma teoria unificada (que ainda não existe, mas tal vez possa ser uma das variantes da teoria das supercordas) explique os fenômenos observados com vários dígitos significativos, vão a surgir discrepâncias. Estas discre-pâncias só serão explicadas pela introdução de novos conceitos e depois, de novas teorias, mais abrangentes. E assim indefinidamente, per secula seculorum. (MAS-FMC/TEOR)
Já, outros quatro que responderam MD, ressaltaram a crítica ao reducionismo.

E um aproveitou para criticar os físicos de partículas e campos:

Nivel de concordância: $M D$

Comentários: Os físicos de partículas venderam seu peixe muito bem! Nos fazem acreditar que eles estão prestes a desvendarem os segredos da natureza... Ninguém tem esse saber! (MOL - AST / EXP)

19 dos participantes que responderam $\mathrm{D}$ comentaram que uma teoria unificada é possível, mas não aceitam a idéia de teoria final. Estas respostas aproximam-se daquelas de três participantes que responderam $\mathrm{MD}$ e de vários outros que responderam A. A semelhança entre algumas respostas A e D explica-se por refletirem a situação dos participantes, em ambos os casos, terem aceitado parte da visão do texto, no caso a unificação, e rejeitado outra parte, no caso a idéia de teoria final, como no exemplo:

Nivel de concordância: $D$

Comentários: Concordo na necessidade em se unificar as teorias das forças básicas da Natureza na forma como a conhecemos atualmente, e que será de grande importância para a compreensão da Natureza. Minha dúvida é: estão tão enraigadas nossas idéias que essas 4 forças descrevem todos os fenômenos que não pensamos na possibilidade de desenvolvimento de um "elo perdido" na Física? Essas 4 forças, só elas existem? Temos acesso a outras dimensões de força ou energia? Há interface dessas dimensões desconhecidas com a nossa? Sim ou não, não podemos acreditar que é possível descrever com completeza todos os fenômenos naturais com as teorias existentes. Há questões em aberto. $(F A C-F M C / E X P)$

Oito dos que responderam D o fizeram por não aceitar a visão reducionista. Como no caso acima, são respostas semelhantes a outras que responderam A. Um exemplo particularmente elaborado desse tipo de resposta é:

Nível de concordância:D

Comentários: Acima já falei sobre o assunto, porém apenas para constar, mesmo reconhecendo os gluons como responsáveis pela interação forte entre quarks, isto não nos permite entender em toda sua extensão diversos aspectos da física dos hadrons. Alguns entendem que os gluons por interagirem fortemente constituem um sistema de muitos corpos que só poderia ser explicado a partir de teorias efetivas similares a encontradas em estado sólido. Em outras palavras, mesmo para um núcleon (nêutron ou próton) não basta conhecer a interação. Como um outro exemplo disto eu posso citar a supercondutividade. Basicamente a única interação importante para este fenômeno é conhecida há muitos e muitos anos (interação coulombiana), entretanto o entendimento da supercondutividade envolve aspectos que ultrapassam o conhecimento desta interação básica. (FRC - NUC / TEOR)

Quatro participantes que responderam D afirmaram não acreditar em uma teoria unificada. O comentário é similar a de alguns que responderam MD, como ilustra a resposta abaixo: 
Nivel de concordância: $D$

Comentários: Esse ponto de vista me parece extremamente otimista. Pressupõe que nossas teorias atuais estão basicamente certas, que a idéia de uma unificação é inevitável como explicação dos fenômenos observados e que não surgirão novos fenômenos muito diferentes dos atualmente observados. Se todas essas hipóteses forem corretas, então a afirmação desse texto está basicamente correta. Do contrário talvez nem mesmo exista uma teoria unificada da forma como a imaginamos hoje! Portanto devo discordar. Uma afirmação como esta deveria sempre vir acompanhada de uma série de ressalvas. (TRS - COS, FPC / TEOR)

Para um dos que respondeu D a idéia contida no Texto 5 é provável, mas irá demorar muito para ocorrer. Neste caso o comentário parece ser de alguém que está mais de acordo:

Nivel de concordância: $D$

Comentários: Este é o conhecimento de hoje. Bastante provável, mas com muitas questões em aberto. Uma teoria que possui 17 parâmetros pode ser considerada apenas um arremedo de uma 'teoria final'. (SNL - FMC / TEOR)

\section{Respostas MA e A}

Doze pessoas, correspondendo a $08 \%$ do total, responderam MA e 36 (24\%) responderam A ao Texto 5, totalizando $32 \%$ dos participantes. Nove dos que responderam MA não fizeram comentários ou apresentaram comentários que pouco acrescentaram ao texto, ou ainda se referiram a comentários feitos no texto precedente. O mesmo ocorreu com 11 dos que responderam A, não sendo possível estabelecer diferenças entre eles.

21 participantes que responderam $\mathrm{A}$ aceitam a idéia de uma teoria unificada, mas não que ela seria a explicação de tudo ou uma fronteira final, nem mesmo dentro da própria física, como na seguinte citação:

Nível de concordância: A

Comentários: A teoria da unificação é certamente um paradigma na física. Acredito que sua elaboração não trará necessariamente um fim à física que conhecemos $e$ sim possibilitará tanto a revisão de inúmeros experimentos e fenômenos atualmente inexplicáveis quanto abrirá ilimitadas possibilidades para elaboração de novas teorias. (CGP - BIO / EXP)

E três dos que responderam A fizeram a ressalva de que pode ser que a unificação não aconteça.

\section{Respostas I}

23 participantes ( $15 \%$ do total) responderam I. A maior parte (14) não apresentou comentários ou fizeram comentários triviais, ou ainda referiram-se a comentários anteriores.

Seis participantes comentaram acreditar em uma teoria unificada, fazendo todavia ressalvas anti-reducionistas. São comentários semelhantes a algumas respostas A e D discutidas acima. Um participante afirmou acreditar em uma teoria unificada, mas não como teoria final. De novo de forma semelhante a algumas das respostas A e D.
Um dos participantes comentou que a maior parte dos cientistas não pensa no assunto. E outro discordou da lógica do texto.

\section{III.2.3 Respostas ao texto 7}

\section{Respostas MA e A}

96 participantes (correspondendo a $63 \%$ do total) responderam MA (46) ou A (50) para o texto. Estes números são consistentes com a rejeição à possibilidade de uma teoria final observada nas respostas aos Textos 4 e 5 .

Dos 45 que responderam MA, 20 não comentaram ou apresentaram comentários triviais, ou fora de contexto, o mesmo ocorrendo para 29 dos 50 que responderam A. O fato do texto abordar um tema já tratado anteriormente explica o alto índice de respostas sem comentário ou com comentários pouco relevantes neste caso. Vários participantes explicitaram este ponto. 13 das respostas MA e 06 das A vieram acompanhadas de afirmativas de que comentários já feitos a textos anteriores justificavam as respostas. Duas respostas dentro desta categoria acrescentaram ainda que, apesar de concordarem, trata-se de uma idéia que não pode ser provada verdadeira. Para um dos que assim responderam a postura é uma questão moral.

Nivel de concordância: $M A$

Pelas respostas que dei antes acho que é óbvio que estou de acordo com isso. Acho porém que esta questão não pode ser provada, mas que é sim uma questão moral. O mais importante que vejo nisso é que se assim não pensarmos estamos sendo preguiçosos e deixando de ser físicos. (CNA $-A S T / E X P)$

Oito das respostas MA e cinco das respostas A acrescentaram comentários ressaltando a idéia do conhecimento como algo inesgotável. Em geral os comentários dos que responderam MA e A não são foram muito distintos também para este texto, como revelam os exemplos que seguem:

Nivel de concordância: $M A$

A ciência não fala das essências das coisas, as quais são, e sempre serão, incognoscíveis. Fazemos um processo de aproximação com teorias que são REPRESENTAÇÕES da natureza. Assim, ciência é por definição um processo inesgotável. (RMA - COS,AST / TEOR)

Nivel de concordância: A

Comentários: Resposta difícil. Acho temerário dizer que "nunca vamos conseguir..." alguma coisa. Mas acho que o mais coerente com meu pensamento expresso nas outras questões é mesmo ficar com a posição cautelosa, e concordar que as teorias mais gerais que possamos conceber não podem, em princípio, serem classificadas como "finais", mesmo que na pratica perdurem por muito tempo. Uma vez que se admita que, em princípio, mesmo uma teoria geral pode ser melhorada ou substituída, pode-se dizer que "não há limites para a busca do conhecimento". Além disso, o conhecimento também pode ser encontrado na aplicação e na busca de detalhes, na complexidade da interação entre diferentes aspectos da natureza. (ZLF-PLA / TEOR) 
$\mathrm{Na}$ mesma linha de pensamento cinco dos que responderam MA fizeram referências à quebra de paradigmas, revoluções e mudanças de interpretação como características do empreendimento científico.

Em quatro das respostas $\mathrm{A}$ apareceram críticas à afirmativa contida no Texto 7 sobre a "essência da realidade" estar sendo aproximada pela física. A crítica apareceu em outros comentários e merece uma discussão. A palavra "essência" gerou uma interpretação, por parte dos participantes, diferente da pretendida quando o texto foi elaborado a partir das citações atribuídas a David Bohm (ver ANEXO I - O Instrumento da Pesquisa). Muitos participantes a interpretaram como algo metafísico, em moldes aristotélicos, quando a intenção na elaboração do texto era a de se referir a uma teoria que explicasse a matéria em termos de seus componentes mais elementares de partículas e campos, no sentido que Weinberg acredita ser possível. Pode-se supor que, não fosse por este ponto, possivelmente as respostas teriam sido MA, como no comentário abaixo:

\section{Nivel de concordância: $A$}

Comentários: Devemos lembrar que os físicos descrevem a natureza através de modelos aproximados e (ou) limitados. A descrição completa de um fenômeno físico não representa a essência final deste mas sim a aparente compreensão adequada e completa do nosso modelo. (MRA ATO,EST,OPT / TEOR)

Um dos participantes comentou que apesar da física estar em uma época de entresafra isso pode mudar, pois os físicos continuam questionando.

Dois dos que responderam A comentaram que a natureza limitada do homem impediria um conhecimento absoluto. Já outro, em uma veia mais mística, acredita ser o conhecimento absoluto possível, mas fora do âmbito da ciência.

\section{Respostas MD e D}

Apenas 26 participantes (17\% do total) responderam MD (10) e D (16) ao Texto 7, mostrando um alto índice de rejeição à idéia de uma teoria final, o que é consistente com os resultados obtidos para textos anteriores. Destes, $08 \mathrm{MD}$ e 02 D não apresentaram comentários, enquanto $02 \mathrm{MD}$ e $02 \mathrm{D}$ apresentaram comentários triviais, confusos ou fora de contexto.

Dos restantes que responderam $\mathrm{MD}$, um aceita a idéia a idéia de um limite para o conhecimento mas acredita estar o mesmo distante, enquanto outro centrou suas crítica na passagem sobre "essência da realidade". O mesmo ocorreu com dois participantes que responderam $\mathrm{D}$, também criticando a passagem relativa a "essência e aparência":

Apenas quatro dos que responderam D comentaram acreditar em uma teoria final, ainda que com ressalvas, como nos caso abaixo:

Nivel de concordância: $D$

Comentários: Embora seja viável uma teoria final, englobando todos os ramos da física, dificilmente poderia-se esperar que os físicos declarem ter chegado à essência da realidade. Sempre pode haver um refinamento de teorias ou de aparelhos que possam detectar níveis mais profundos da mesma. (TAS-ENS,FMC / EXP)

Três das respostas D vieram acompanhadas de comentários que mostram que seus autores na verdade concordam com o cerne do Texto 7, ou seja que o conhecimento é inesgotável. A discordância ocorreu com relação à afirmativa de que físicos modernos falam de uma teoria final ou pressupõem ser possível atingir a essência da realidade. $\mathrm{Na}$ verdade estas respostas ficariam melhor caracterizadas como A. O exemplo esclarece o ponto:

Nível de concordância: $D$

Comentários: O fato de haver uns poucos físicos que pressupoem chegarem a uma quintessência da realidade, não fala por todos os cientistas. Evidentemente, a nossa percepção da realidade mudou e com ela mudaram as fronteiras do conhecimento tangível. O processo de aprendizado é contínuo e que sempre nos remete a fonte. No fim do século XIV muitos físicos julgaram que a natureza poderia ser completamente descrita pelo cartesianismo, darwinismo, etc. e que apenas ajustes menores seriam precisos para descrever a lei matemática que é "Deus". Os verdadeiros cientistas dignos deste nome atualmente dizem o contrário, e são mais abertos que muitos filósofos. O corpo e a essência são parte de um todo, separados antes, juntos agora para sempre. (SAM - FAI,FMC / EXP)

Um dos participantes respondeu D por acreditar ser impossível afirmar com certeza algo sobre o assunto, tanto em um sentido quanto no outro:

Nível de concordância: $D$

Comentários: Não sei se isso é mais verdade do que dizer que há uma essência da realidade e que nós estamos nos aproximando dela. Simplesmente não sei. A própria crença de que o Universo é explicável por meio de regras que chamamos de "Leis Naturais" é uma crença que não pode ser provada, apesar de nossa experiência até hoje mostrar que essa crença é razoável. Dizer que não há limites para a busca do conhecimento é tão arbitrário quanto dizer que estamos próximos da "Teoria de Tudo" e do "Fim da Ciência”. Acho que qualquer afirmação a esse respeito é mero dogma de fé. (TRS - COS,FPC / TEOR)

E uma das respostas D veio acompanhada de um comentário situando os limites da busca do conhecimento em nossa capacidade cognitiva, e também criticando a relação essência-aparência.

\section{Respostas I}

Trinta participantes (20\% do total) responderam I para o Texto 7. Destes, onze não fizeram comentários e outros três apresentaram comentários fora de contexto, de difícil entendimento, ou ainda sem muita relevância.

Cinco responderam I por pensarem ser impossível prever o que irá acontecer, sendo que alguns acreditam que a preocupação com o tema não é científica. Por exemplo:

Nivel de concordância: I

Comentários: Não temos condições de dizer que existirá, ou não existirá, uma "teoria final”. Essa preocupação não é cientifica. O papel do físico é investigar a natureza. 
Os modelos que são construidos são reflexo das observações realizadas e a direção que eles vão tomando não podem ser predeterminadas pelos cientistas. $(P A S-F P C / E X P)$

Numa linha similar, outros dois participantes acreditam ser esta uma questão com as quais os físicos, em geral, não se envolvem.

Duas respostas I vieram acompanhadas de comentários que admitem a possibilidade de uma Teoria Final, sem que tal signifique o fim da Física. Este tipo de comentário encontra-se bem alinhado com a posição defendida por Weinberg, como no caso abaixo:

\section{Nivel de concordância: I}

Comentários: Aqui acho que tem que haver um pouco mais de precisão na afirmativa. É até possivel ter uma espécie de fisica básica 'final' no sentido realmente de leis e fenômenos básicos. Mas isto não esgotaria os problemas de interesse físico pois a complexidade do Universo é tão grande que sempre teremos de encontrar respostas $e$ explicações para fenomenos importantes, ainda que as leis básicas seja conhecidas.(CMC-EST,FMC / TEOR)

E seis responderam I por considerarem o texto confuso ou sem muito sentido.

\section{Conclusões}

As idéias refletindo crenças em uma teoria final unificada e em uma visão reducionista hierárquica foram apresentadas nos Textos 4 e 5, enquanto o Texto 7 é de oposição à possibilidade de uma teoria final. Tais idéias aparecem de forma emaranhada nos Textos 4 e 5, o que causou dificuldades em separá-las para o caso dos participantes que apresentaram comentários que foram aproveitados para análise. Isso correspondeu aproximadamente à metade da amostra; os demais não apresentaram comentários, ou fizeram comentários que pouco acrescentaram à discussão, ou ainda os argumentos eram de difícil compreensão.

Na figura abaixo estão representados os percentuais de respostas aos textos aqui analisados. Em geral pode-se afirmar que existe uma baixa tendência de aceitação das idéias contidas no Texto 4 (31\% MD; 35\% D; $16 \%$ I; $14 \%$ A; $04 \%$ MA) e no Texto 5 (14\% MD; 39\%; D; $15 \%$ I; $24 \%$ A; $08 \%$ MA) e uma baixa tendência de rejeição às idéias do Texto 7 (07\% MD; $10 \%$ D; 20\% I; 33\% A; 30\% MA), o que revela consistência nos padrões de resposta. As respostas MA para os Textos 4 e 5 e MD para o Texto 7 refletem claras tendências de baixa aceitação e alta rejeição à possibilidade de uma teoria final e do reducionismo hierárquico. Já as respostas A e D muitas vezes apresentaram comentários semelhantes às MA e MD, mas em outros casos foi possível definir a razão da resposta não ter sido "muito" de acordo ou em desacordo com o teor dos textos. Nesses casos isto era devido ao emaranhamento das idéias referentes à teoria final e reducionismo nos textos do instrumento de pesquisa. $\mathrm{Ou}$ seja, casos em que os comentários refletiam uma crença no reducionismo, mas não na teoria final, ou vice-versa.

\section{Respostis aos Textos 4,5 e 7 (Em \%)}

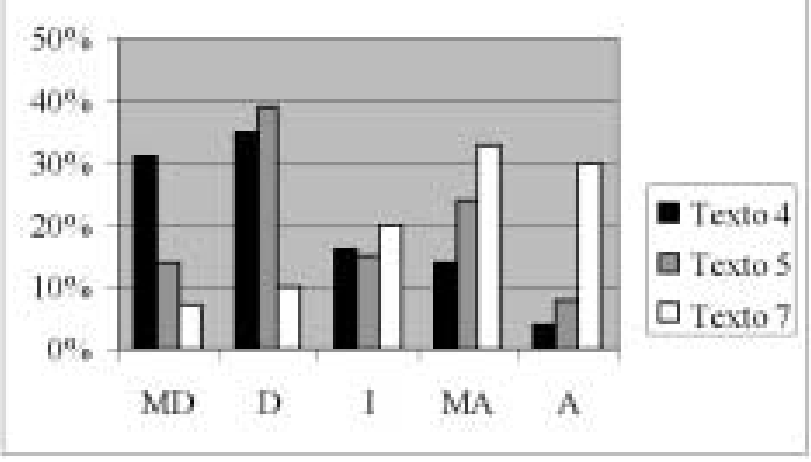

A análise mais detalhada dos comentários referentes a respostas A, D e I nos Textos 4 e 5 sugere que, das idéias apresentadas, as mais rejeitadas são as referentes à teoria final e reducionismo, e revelam a predominância da crença na ciência como uma busca infindável do conhecimento e na natureza como muito complexa para ser conhecida de forma final. Por outro lado, a idéia de unificação foi a que recebeu menos comentários contrários, sendo possível dizer que esta idéia é mais aceitável, desde que não venha associada com as outras.

Por exemplo, dos participantes que responderam A para o Texto 5, 10 aceitam a idéia de uma teoria unificada, mas não que ela seja a explicação de tudo ou uma fronteira final, nem mesmo dentro da própria física para alguns, e outros 11 o fizeram pelo motivo de que, mesmo acreditando na elaboração de uma teoria unificada não a vêm como uma teoria final, mas sim como uma porta para o surgimento de novos problemas para investigação. Por sua vez, 19 dos 59 participantes que responderam $\mathrm{D}$ ao Texto 5 comentaram que uma teoria unificada é possível, mas não aceitam a idéia de teoria final. Estas respostas aproximam-se daquelas de três participantes que responderam MD e de vários outros que responderam A ao texto. Já, 08 dos que responderam D o fizeram por não aceitar a visão reducionista. Como no caso acima, são respostas semelhantes a outras dos que responderam A.

A semelhança entre algumas respostas A e D explica-se por refletirem a situação dos participantes, em ambos os casos, terem aceitado parte da visão do texto, a unificação, e rejeitado outra parte, a idéia de teoria final. E, 06 de 09 participantes que responderam I ao Texto 5 comentaram acreditar em uma teoria unificada, fazendo todavia ressalvas anti-reducionistas; um afirmou acreditar em uma teoria unificada, mas não como teoria final. Fica clara aqui a crença na ciência como um desvendar infinito da natureza.

Apenas um dos participantes que respondeu MA ao Texto 5 e outro que respondeu A comentaram que a teoria final será provavelmente a de supercordas, sendo que o segundo fez a ressalva de que sempre irá restar um resquício de dúvida se não haveria uma teoria ainda mais fundamental. 
A tendência de rejeição à idéia de uma teoria final é confirmada pela análise das respostas ao Texto 7 , que defende a busca do conhecimento a respeito da natureza como algo inesgotável, e que teve apenas $17 \%$ de respostas MD e D. Os comentários mais comuns nesta linha foram no sentido de ressaltar a idéia do conhecimento como uma busca sem fim, havendo também referências à quebra de paradigmas, revoluções e mudanças de interpretações como características do empreendimento científico. Deve-se notar ainda que 05 das respostas MD e D vieram acompanhadas de comentários que permitem supor que os seus autores estavam principalmente em desacordo com a expressão "essência da realidade", e não necessariamente com a idéia de um desvendar sem fim da natureza. De todos os comentários ao Texto 7 , pode-se dizer que apenas algo em torno de 5\% foram efetivamente reveladores de crença em uma teoria final para a física, e mesmo assim com alguma forma de ressalva.

Desta forma, pode-se concluir que apesar de ser defendida por físicos de renome, como o caso de Steven Weinberg, a possibilidade de uma Teoria Final Unificada não se mostrou uma idéia popular na comunidade consultada, o mesmo acontecendo, em menor escala, com o reducionismo hierárquico $^{14}$. Já, a unificação mostrou-se mais bem aceita, desde que dissociada da idéia de uma teoria final.

A rejeição da perspectiva de uma teoria final não é surpreendente. Afinal, a noção de que a exploração da natureza pode sempre conduzir a descobertas inesperadas e novas revoluções parece ser parte obrigatória da formação dos físicos: dificilmente um estudante não tomou contato, nas introduções à física moderna, com alguma referência à crença da comunidade de físicos do final do século XIX de que pouco mais havia para ser feito na área, em termos de grandes desenvolvimentos teóricos. Outros dados do estudo mais amplo, do qual os resultados apresentados no presente artigo fazem parte, evidenciam um amplo antagonismo, por parte dos participantes, à perspectiva do "fim da ciência" defendida por Horgan (1998).

A aventada rejeição do reducionismo, no entanto, é mais difícil de explicar, uma vez que tal perspectiva é geralmente vista como uma tradição forte da ciência moderna (Cat 1998; Pleitez 2000). É possível a rejeição tenha aparecido, em parte, como um efeito induzido pelo instrumento da pesquisa, já que nos Textos 4 e 5 o reducionismo aparecia juntamente com a idéia, comprovadamente pouco aceita, de uma teoria final. Trata-se de um ponto que merece ser mais investigado.

\section{Referências}

ABRANTES, P. Imagens de natureza, imagens de ciência. Papirus Editora, São Paulo, 1998.

CAT, J. The physicists' debate on unification in physics at the end of the $20^{\text {th }}$ century. Historical Studies in the Physical and Biological Sciences, 28 (2), p. 254-299, 1998.
DIEKS, D. The scientific view of the world: introduction. In: Hilgevoord, J. (Ed.) Physics and our view of the world. Cambridge University Press, Cambridge, 1994.

EL-HANI, C.N. e PEREIRA, A.M. Reducionismo ou holismo: desperguntando a questão. Ideação, Feira de Santana, 3, p. 69-100, 1999.

EL-HANI Uma ciência da organização viva: organicismo, emergentismo e ensino de biologia. In: SILVA FILHO, W. J. Epistemologia e ensino de ciências. DP\&A, São Paulo, no prelo.

GREENE, B. O universo elegante: supercordas, dimensões ocultas e a busca da teoria definitiva. Companhia das Letras, São Paulo, 2001.

HAWKING, S.W. Uma breve história do tempo: do bigbang aos buracos negros. Rocco, Rio de Janeiro, 1988.

HILGEVOORD, J. Introduction. In: Hilgevoord, J. (Ed.) Physics and our view of the world. Cambridge University Press, 1994.

HOLTON, G. The thematic imagination in science. In: Holton, G. Thematic origins of scienetific thought: Kepler to Einstein. Harvard University Press, Massachusetts, 1973.

HOLTON, G. Os temas do pensamento científico. In: Holton, G. A imaginação científica. Zahar, Rio de Janeiro, 1979.

't HOOFT, G. Theories of everything. In: Hilgevoord, J. (Ed.) Physics and our view of the world. Cambridge University, Cambridge University Press, 1994.

HORGAN, J. O fim da ciência: uma discussão sobre os limites do conhecimento científico. Companhia das Letras, São Paulo, 1998.

KEVLES, D. Preface 1995: The death of the superconductinc super collider in the life of American physics. The Physicists, Harvard University Press, Massachusetts, 1995.

KUHN, T. S. A estrutura das revoluções científicas. Perspectiva, São Paulo, 1975.

LUZZI, R. Está a física chegando ao seu fim? In: Pessoa Jr., O. (org) Fundamentos da Física 1 Simpósio David Bohm. Editora Livraria da Física, São Paulo, 2000.

MAYR, E. O desenvolvimento do pensamento biológico. Editora da UNB, Brasília, 1998.

MOTA, L.M. As controvérsias sobre a interpretação da mecânica quântica e a formação dos licenciados em física (um estudo em duas instituições: UFBA e UFSC). Dissertação de Mestrado, Programa de Pós-Graduação em Educação da UFSC, 2000.

OSTERMANN, F. e CAVALCANTI, C.J. de H., Física moderna e contemporânea no ensino médio: elaboração de um material didático em forma de pôster, sobre partículas elementares e interações fundamentais. Caderno Catarinense de Ensino de Física, 16 (3), p. 267-286, 1999.

PLEITEZ, V. À procura das leis fundamentais. Revista Brasileira de Ensino de Física, 22 (2), p. 176-188, 2000.

PRIGOGINE, I. and STENGERS, I. A nova aliança. Editora Universidade de Brasília, Brasília, 1984.

\footnotetext{
${ }^{14}$ Os resultados foram apresentados de forma global, sem distinção de áreas de atuação. Uma hipótese inicial de que físicos de partículas e campos teriam uma tendência a discordar menos dos Textos 4 e 5 e discordar mais do Texto 7, quando comparados com físicos da área de matéria condensada e de física estatística, não foi confirmada por uma análise mais fina dos dados.
} 
SMOLIN, L. Três caminhos para a gravidade quântica. Rocco, Rio de Janeiro, 2002.

WEINBERG, S. Dreams of a final theory: the search for the fundamental laws of nature. Vintage, London, 1993. (Edição brasileira: Sonhos de uma teoria final, Rocco, Rio de Janeiro, 1996)

WEINBERG, S. A unified physics by 2050 ? Scientific American, p. 36-43, December 1999.

WEINBERG, S. Will we have a final theory of everything? Time, p. 50-51, April 10, 2000.

WEINBERG, S. Os limites da explicação científica. $C a$ derno Mais! Folha de São Paulo, p. 7-12, 24 de Junho de 2001.

ZANETIC, J. Física também é Cultura. Tese de Doutorado, Faculdade de Educação da USP, 1989.

\section{Anexo I}

\section{O Instrumento da Pesquisa}

Observação: No espaço reservado para os comentários dos participantes foram colocadas as razões que levaram à escolha dos textos pelo pesquisador e de onde os mesmos foram originados. Essas informações não constavam do instrumento da pesquisa.

Os textos curtos apresentados a seguir expressam pontos de vista com relação ao estado atual da ciência em geral, e da física em particular, e seus desenvolvimentos futuros.

Para cada um dos textos, por favor:

a) indique o seu nível de concordância através dos símbolos MA, A, I, D, MD, de acordo com a seguinte tabela:

MA Muito de acordo

A De acordo

I Indiferente

D Em desacordo

MD Muito em desacordo

b) comente os motivos que conduziram à sua apreciação. Isso será de muita valia para a análise a ser feita, principalmente nos casos em que você não escolheu a opção MA.

\section{Texto 1}

Se alguém acredita na ciência deve aceitar a possibilidade - até a probabilidade - de que a grande era das descobertas científicas tenha chegado ao fim. A ciência pura, a busca do conhecimento sobre o que somos e de onde viemos, já entrou numa era de resultados decrescentes. A maior barreira para o progresso futuro é, sem dúvida, o seu sucesso passado. Os pesquisadores já mapearam a realidade física, do microcosmo dos quarks ao macrocosmo dos planetas, estrelas e galáxias. Devido ao progresso que a ciência já alcançou e tendo em vista os limites físicos, sociais e cognitivos que restringem a pesquisa futura, é improvável que a ciência faça acréscimos significativos ao conhecimento que já gerou.

\section{Nível de concordância:}

\section{Comentários:}

O texto resume as idéias de John Horgan sobre o fim da ciência, e foi montado com frases extraídas de Horgan
(1988). A primeira e a última frases encontram-se na página 17 e as outras nas páginas 29 e 30.

\section{Texto 2}

Os cientistas não devem concluir que a pesquisa pura esteja fadada a degenerar, tornando-se um simples preenchimento de detalhes; é sempre possível que uma de suas experiências tenha importância revolucionária, comparável à da mecânica quântica ou da teoria de Darwin. Por exemplo, na virada do século, os físicos diziam que a maior parte da física estava resolvida. Havia ainda alguns problemas incômodos, mas estava basicamente resolvida. E descobrimos que não era nada disso. Na verdade, o que percebemos é que esse tipo de pensamento costuma ser um indício de que outro grande progresso está por acontecer. Sempre que se pensa que o fim está à vista, descobre-se que esta idéia abre uma perspectiva inteiramente nova do universo. É isso o que talvez vá acontecer.

\section{Nível de concordância: \\ Comentários:}

O texto apresenta uma idéia oposta ao do anterior. A primeira frase aparece na página 44 de Horgan (1998), na qual o autor apresenta idéias do filósofo Nicholas Rescher. O restante do texto foi extraída de uma citação do cosmólogo David Schramm, que aparece na página 134 do mesmo livro.

\section{Texto 3}

Uma quantidade cada vez maior de trabalho e gastos financeiros tem se mostrado necessária para sustentar o progresso científico. Mais cedo ou mais tarde, teremos de parar, por causa dos limites insuperáveis da mão de obra e do financiamento. Tão rápido tem sido o crescimento da ciência em nosso século que criamos a ilusão de pensar que poderemos manter esse ritmo de progresso indefinidamente. É bastante evidente que devemos colocar freios na quantidade de financiamento para a ciência, a ciência pura. Neste sentido a decisão do Congresso dos Estados Unidos, em 1993, que pôs fim ao superacelerador por supercondutividade ("superconducting supercollider"), orçado em 8 bilhões de dólares foi essencialmente correta.

\section{Nível de concordância:}

\section{Comentários:}

O texto defende a decisão do congresso americano em suspender a construção do superacelerador. Ela foi adaptada a partir de citações do biólogo Bentley Glass, que foi presidente da Associação Americana Para o Progresso da Ciência, em 1971. As citações aparecem na página 40 de Horgan (1998).

\section{Texto 4}

Algum dia chegaremos a uma teoria final da física, o que será a realização mais fundamental possível da ciência - o alicerce de qualquer outro conhecimento. Sem dúvida, alguns fenômenos complexos, como a turbulência, a supercondutividade em altas temperaturas, a economia ou a vida, exigem suas próprias leis e generalizações especiais. Mas se perguntarmos porque esses princípios são verdadeiros essa 
pergunta nos leva à teoria final da física, sobre a qual tudo repousa. É isso que faz da ciência uma hierarquia. É uma hierarquia e não apenas uma rede aleatória.

\section{Nível de concordância:}

\section{Comentários:}

Texto que apresenta as idéias de Weinberg sobre uma teoria final e, principalmente, a sua visão reducionista. Foi adaptado a partir de citações àquele físico por Horgan (1998) e aparecem na página 99 do livro.

\section{Texto 5}

A atual teoria de partículas elementares e forças, conhecida como o Modelo Padrão, unificou o eletromagnetismo com as interações fracas. O modelo também dá uma descrição separada mas similar das interações fortes. Temos idéias de como a teoria das interações fortes pode ser unificada com a teoria das interações fracas e eletromagnéticas, mas talvez isso funcione apenas se a força gravitacional for incluída, o que apresenta grandes dificuldades. É impossível dizer quando estas dificuldades serão superadas. Os problemas existentes podem ser resolvidos amanhã, ou ainda não terem sido solucionados daqui a 100 anos. Mas quando eles forem resolvidos teremos descoberto uma teoria unificada que descreverá a natureza em todas as energias. Quando isso acontecer teremos chegado ao final de um certo tipo de física: a busca de uma teoria unificada da qual decorreriam necessariamente todos os outros fatos da ciência física.

\section{Nível de concordância:}

\section{Comentários:}

O texto apresenta de forma sumária o Modelo Padrão e a visão de Weinberg sobre a unificação definitiva e reducionista na física. Ele foi adaptado de frases que aparecem em Weinberg (1999), nas páginas 37-38 e 43.

\section{Texto 6}

O conhecimento científico é o resultado de um processo de negociação entre cientistas, no qual aspectos ligados a prestígio e poder são fundamentais. A ciência é determinada por tais fatores sociais, não se podendo afirmar, em absoluto, que ela reflete as características de um mundo externo independente. As partículas elementares que aparecem no Modelo Padrão não podem então ser consideradas como existindo independentemente dos cientistas, porque elas são literalmente construídas pelos pesquisadores. Após um complicado processo de negociação, a comunidade científica atinge um consenso a respeito de certos experimentos e sua interpretação - por exemplo que os resultados serão explicados como indicando a existência de quarks. Mas essa situação final apenas reflete as relações de poder e interesse na comunidade científica.

\section{Nível de concordância:}

Comentários:

O texto apresenta a visão construtivista-social. É uma adaptação quase literal do que aparece nas páginas 72-73 de Dieks (1994).

\section{Texto 7}

Não há limites para a busca do conhecimento. Os físicos falarão da teoria final, mas esse é um pressuposto que não tem fundamento. Em cada nível, temos algo que é tomado como aparência, e alguma outra coisa é tomada como a essência que explica a aparência. Mas quando passamos a outro nível, a essência e a aparência trocam de regras. Não há fim para a busca. A própria natureza de nosso conhecimento é dessa natureza. A ciência é um processo inesgotável. Os físicos modernos pressupõem que estão se aproximando da essência da realidade. Se eles acreditarem nisso deixarão de fazer as perguntas realmente profundas. Nunca vamos conseguir a essência final que não seja também a aparência de alguma coisa.

\section{Nível de concordância:}

Comentários:

O texto apresenta uma visão contrária a uma Teoria Final e também ao reducionismo. Ele foi adaptado a partir de citações atribuídas a David Bohm, extraídas da página 115 de Horgan (1998).

Você acha importante discutir com os alunos a temática abordada nos textos acima?

SIM___ NA: GRADUAÇÃO__- PÓS-GRADUAÇÃO_-_ ENSINO MÉDIO_-

NÃO_-

Você discute essa temática com seus alunos?

SIM_-_ NÃO

Em que disciplinas?

Caso você tenha comentários adicionais sobre esse estudo, por favor, faça-os a seguir. Obrigado!

\section{Anexo II}


Áreas de Atuação:

ATO - Física Atômica e Molecular 14

AST - Astrofísica, Astronomia e Geofísica 10

BIO - Biofísica 07

CLA - Áreas Clássicas da Física 07

COS - Cosmologia e Gravitação 13

ENS - Ensino de Física 23

EST - Física Estatística 18

FAI - Física Aplicada na Indústria 08

FPC - Física de Partículas e Campos 24

FMC - Física da Matéria Condensada 54

MED - Física Médica e Dosimetria 09

MLD - Multidisciplinar 17

NUC - Física Nuclear 21

OPT - Óptica 20

PLA Física de Plasmas 10
Formas de Atuação :

TEOR - Teórica 147

EXP - Experimental 122

IND - Industrial 05

Observação: As somas ultrapassam o número de participantes porque muitos aparecem no Diretório 1999-2000 da SBF com mais de uma área ou forma de atuação.

\section{Instituições}

IFUSP 31 UFRJ 23 UFSC 11 UNICAMP 09 CBPF 07 INPE 07 USP-SCar 05 IFT 05 UFMG 05 CNEN 05 UFRN 04 UFRGS 04 UERJ 04 UFC 04 UFBA 03 UFPE 03 UEL 03 OUTRAS 19 